\title{
Morphology of transcriptional units at different states of activity
}

\author{
By W. W. Franke and U. SgheER \\ Division of Membrane Biology and Biochemistry, Institute of Experimental Pathology, \\ German Cancer Research Centre, Heidelberg, Federal Republic of Germany
}

[Plates 1-4]

\begin{abstract}
The morphology of two forms of transcriptionally active chromatin, the nucleoli and the loops of lampbrush chromosomes, has been examined after fixation in situ or after isolation and dispersion of the material in media of low ionic strengths, using a variety of electron microscopic preparation techniques (e.g. spread preparations with positive or negative staining or without any staining at all, with bright and dark field illumination, with autoradiography, after pretreatment of the chromatin with specific detergents such as Sarkosyl NL-30; transmission and scanning transmission electron microscopy of ultrathin sections). Nucleolar chromatin and chromosomes from oocytes of various amphibia and insects as well as from green algae of the family of the Dasycladaceae were studied in particular detail. The morphology of transcriptional units that are densely packed with lateral ribonucleoprotein fibrils, indicative of great transcriptional activity, was compared with that of chromatin of reduced lateral fibril density, including stages of drug-induced inhibition. The micrographs showed that under conditions which preserve the nucleosomal organization in condensed chromatin studied in parallel, nucleosomes are not recognized in transcriptionally active chromatin. This holds for the transcribed regions as well as for apparently untranscribed (i.e. fibril-free) regions interspersed between ('spacer') and/or adjacent to transcribed genes and for the fibril-free regions within transcriptional units of reduced fibril density. In addition, comparison of lengths of repeating units of isolated rDNA with those observed in spread nucleolar chromatin indicated that this DNA is not foreshortened and packed into nucleosomal structures. Granular particles which were observed, at irregular frequencies and in variable patterns, in some spacer regions, did not result in a proportional shortening of the spacer axis, and were found to be resistant to detergent treatment effective in removing most of the chromatin associated proteins including histones. Thus, these particles behave like RNA polymerases rather than nucleosomes.

It is suggested that structural changes from nucleosomal packing to an extended form of DNA are involved in the transcriptional activation of chromatin.
\end{abstract}

\section{INTRODUCTION}

It has been demonstrated that, in a variety of cell nuclei, major portions of the chromatin are organized in the form of nucleosomes, i.e. granular particles of 10-12 nm diameter which are arranged in a characteristic beaded chain (for descriptions of nucleosome organization and relevant literature see other contributions in this symposium). One of the important questions, however, is whether the nucleosomal organization is maintained in chromatin active in transcription or whether the transcribed chromatin assumes a different, perhaps specific, architecture. That chromatin consists of a heterogeneous mosaic of dispersed and condensed ('chromocentres') moieties, at least some of which correspond to specific regions of the metaphase chromosnmes, is an old and well established cytological experience (for review see Heitz 1932), and it was Heitz who first correlated differences in the degree of stainability and 
DNA packing density with the specific transcriptional activity of the genes located in these chromatin regions. There are two principally different methodical approaches to study the structural organization of chromatin active in transcription. One way is to fractionate chromatin into condensed and dispersed material and, what should be more or less corresponding, into transcriptionally inactive and active chromatin, the latter being primarily characterized by its association with ribonucleoprotein material containing the nascent RNAs (for references on methods and problems of this approach see, for example, Berkowitz \& Doty r975; Krieg \& Wells 1976; Rickwood \& Birnie 1976; Gottesfeld 1978, this symposium). The alternative approach is to selectively isolate more or less distinct, cytologically defined nuclear structures, mostly by manipulatory techniques, and to study the structure of these selected units (see also Daneholt et al. 1978, this symposium; Sommerville, Malcolm \& Callan 1978, this symposium). While the first described approach has the advantage of providing masses sufficient for biochemical analyses, the latter strategy allows the preparation of small amounts of chromatin material and thus usually is less favourable to biochemical analysis, so that its examination frequently is restricted to light and electron microscopy. On the other hand, cross-contamination in general is a severe problem with the first technique, whereas the manipulation allows one to prepare highly purified chromatin structures and to directly control the degree of purity during the preparation. In the following we describe and discuss electron microscopic observations in relatively well defined nucleolar and non-nucleolar chromatin units prepared by manipulatory techniques from isolated nuclei. These observations support the concept that in transcriptionally active chromatin the DNA is rather extended and is not included in nucleosomes. In this discussion the following morphological and biochemical terms will be used (see, for example, Miller \& Beatty 1969; Miller \& Bakken 1972; Spring et al. 1974; Franke et al. 1976a; Scheer, Franke, Trendelenburg \& Spring 1976b; Trendelenburg, Scheer, Zentgraf \& Franke 1976).

Intercept: the region of a chromatin strand between any two given reference points in transcriptional events.

Transcriptional complex: the chromatin-associated particle containing RNA polymerase and the attached nascent ribonucleoprotein (RNP) fibril.

Transcriptional unit: the intercept that is transcribed by a RNA polymerase into one covalent ribopolynucleotide, i.e. an intercept limited by a promoter and a terminator site.

Matrix unit: the intercept covered with series of lateral fibrils which increase in length from one point (the starting point) or, at least, all of which are longer than the fibril at the starting point (the latter to allow for potential processing events or higher packing density of the nascent RNA which may lead to subsequent fibril shortening). Sometimes matrix unit is used synonymously with transcriptional unit.

Spacer unit or apparent spacer unit: the morphologically identified intercepts not covered with lateral fibrils, which lie between matrix units.

$H n-R N A$ : heterogeneous nuclear RNA, a class of RNA of high molecular mass, which contains precursor molecules to mRNA (pre-mRNA).

Pre-rRNA: the largest size class of stable molecules that contain $28 S$ and $18 S$ rRNA sequences ( $S$ values of ribosomal RNAs are nominal).

rDNA: DNA that is enriched in, and may exclusively consist of, the genes for the common precursors to $18 S$ and $28 S$ rRNAs and the interspersed apparent spacer regions.

$r D N A$ spacer unit:' regions in repeating units of $\mathrm{rDNA}$ that do not contain sequences 
complementary to pre-rRNA or to RNA which is transcribed from the same promoter as the pre-rRNA.

$r D N A$ repeating unit: the unit consisting of transcriptional unit for pre-rRNA and the adjacent (subsequent or preceding) spacer.

The type of preparation most frequently used in these studies included a brief dispersion of the chromatin material in solutions of very low ionic strengths at slightly alkaline $\mathrm{pH}$ values (pH 8-9) followed by centrifugation or adsorption of the material, with or without fixation in formaldehyde, onto thin films (for preparative conditions see Miller \& Beatty 1969; Miller \& Bakken 1972; Spring et al. 1974; Franke et al. 1976b). Under these conditions 'normal' chromatin, especially condensed chromatin, appears as nucleosomal 'beaded chains' (see Olins \& Olins 1974; Franke et al. 1976b; Woodcock, Safer \& Stanchfield 1976b). Hence, such methods do preserve the nucleosomal organization present in vivo, at least in major parts of the chromatin. Under the same preparative conditions the following types of chromatin appeared not to contain nucleosomal structures.

TRANSGRIPTIONAL UNITS OF GENES CODING FOR PREGURSORS TO RIBOSOMAL

RNAS AT HIGH DENSITIES OF TRANSGRIPTIONAL GOMPLEXES

In electron micrographs of spread preparations of transcriptionally active nucleoli the genes coding for pre-rRNA are recognized in characteristic arrays of tandemly arranged matrix units separated by more or less extended apparent spacer regions (figures 1-4, plate 1; figures 5-7, plate 2; figures 8, 9, 11, 12, plate 3; figure 10; cf. Miller \& Beatty 1969; Miller \& Bakken 1972; Trendelenburg, Spring, Scheer \& Franke 1974; Franke et al. 1976a; McKnight \& Miller 1976: Spring et al. 1976; Puvion-Dutilleul, Bernadac, Puvion \& Bernhard 1977; Scheer, Trendelenburg, Krohne \& Franke 1977). Such strands of transcriptionally active nucleolar chromatin can appear either as long units, be they of chromosomal or extrachromosomal origin (figures 1-4, 9; cf. references quoted above), or as relatively small circular units of amplified extrachromosomal nature such as in the oocytes of various amphibia and insects (figure 8; see also Miller \& Beatty 1969; Scheer, Trendelenburg \& Franke 1976a; Trendelenburg et al. 1976; Trendelenburg, Franke \& Scheer 1977). Granular structures of 10-14 nm diameter are characteristically found at the bases of the lateral fibrils and are interpreted as representing the RNA-polymerase A complexes involved in the elongation of the RNA of the specific attached lateral fibril (see references quoted above). In complete matrix units these basal granules are in almost close packing and therefore would not leave space for additional granular structures of the same size class such as nucleosomes (figures 2-11; for detailed discussion see Franke et al. 1976 b). In some types of nuclei and nucleoli, though not in all, the length of the whole matrix unit corresponds to the size of the pre-rRNA isolated, assuming that the DNA is present in an extended $B$ form (for examples of exceptions in which the DNA of the matrix unit seems to code for much more than the specific pre-rRNA see Trendelenburg et al. 1976; Franke et al. 1976a). That the DNA contained in the matrix unit is present in an extended B conformation is also indicated by the correspondence of the size class distribution of the circular rDNA molecules from Dytiscus and Acheta oocytes with that of the rings of transcribed nucleolar chromatin from these nuclei (figure 8; for detailed analysis see Trendelenburg et al. 1976). Such a correspondence is particularly striking with the smallest size class of rings observed, i.e. those containing one pre-rRNA gene and spacer and having a 
molecular mass of approximately $14 \times 10^{6}$ (Trendelenburg et al. 1976). An especially clear demonstration of a correspondence of lengths of repeating units of rDNA in isolated DNA and in transcribed nucleolar chromatin has come from the comparison of data obtained with restriction endonuclease cleavage of rDNA with measurements of rDNA repeating units in spread chromatin in Xenopus laevis (figure 10; Wellauer et al. 1974; Wellauer \& Reeder 1975; Franke $e t$ al. 1976b; Wellauer, Dawid, Brown \& Reeder 1976a; Wellauer, Reeder, Dawid \& Brown 1976b; Buongiorno-Nardelli, Amaldi, Beccari \& Junakovic 1977; Scheer et al. 1977). The absence of nucleosomal particles in densely covered matrix units of spread pre-rRNA genes is not only observed with positive staining (figure 6; see also Foe, Wilkinson \& Laird 1976; Laird, Wilkinson, Foe \& Chooi 1976; McKnight \& Miller 1976; Woodcock, Frado, Hatch \& Ricciardello $1976 a$ ) but also with negative staining and without any additional staining at all (Trendelenburg \& Franke, unpublished results) as well as in dark field illumination (figure 5). Their absence can also be concluded from the constancy of the number of $10-14 \mathrm{~nm}$ granules in matrix units of nucleolar chromatin with and without pre-treatment with solutions containing the detergent Sarkosyl NL-30 which release most of the chromatin proteins, histones included, from the DNA-containing axis but leave the transcriptional complexes already initiated (figures 11 and 12; see also below and Franke et al. 1976b; see Scheer et al. (1977) and Gariglio (1976) for references on the action of Sarkosyl).

\section{DESGRIPTION OF PLATE 1}

Figures 1-4. Electron micrographs of positively stained spread preparations of isolated nucleolar chromatin.

FIGURE 1. Sequence of tandemly arranged transcriptional units of genes coding for the precursor molecules to ribosomal RNAs in nucleolar chromatin isolated from the primary nucleus of the green alga Acetabularia mediterranea (cf. Spring et al. 1976). Note the relatively short regions free of lateral fibrils, i.e. the apparent 'spacer' intercepts. (Magn. × 5900.)

Figure 2. Higher magnification (photographically enhanced contrast) of a transcriptional unit in nucleolar chromatin from Acetabularia major during the formation of lateral fibrils containing the nascent precursors to ribosomal RNAs. Note the close packing of the lateral fibrils on the rDNA-containing chromatin axis. (Magn. $\times 65000$.

FIGURE 3. Two transcriptional units of genes coding for the precursor to ribosomal RNAs with the interspersed fibril-free 'spacer' region (arrow) in nucleolar material isolated from lampbrush stage oocytes of Triturus cristatus. Note the high density of lateral fibrils. (Magn. $\times 23000$.)

FIGURE 4. Positively stained and metal-shadowed chromatin axis isolated from fully transcribed nucleoli of Triturus alpestris oocytes (cf. Scheer et al. I976a). Granular particles without attached lateral fibrils are sometimes observed in apparent spacer regions (arrows). Their number and pattern of arrangement is highly variable, and their number is not inversely correlated with the length of the specific spacer unit (cf. Franke et al. $1976 \mathrm{~b}$ ). This indicates that these particles do not represent nucleosomes. (Magn. $\times 38000$.)

\section{DESGRIPTION OF PLATE 2}

FIGURE 5. Electron micrograph showing spread nucleolar chromatin from an oocyte of Xenopus laevis (lampbrush stage) in dark field illumination. Note the occurrence of granular particles at the bases, resulting in a generally thickened appearance of the matrix unit axis, and at the free ends of the lateral fibrils of the transcriptional units (some are denoted by arrows). (Magn. $\times 25000$.)

FIGURE 6. Similar preparation as that shown in figure 5 obtained from an oocyte of a 1-nu mutant of Xenopus laevis (cf. Scheer et al. 1977 ) and revealed in negative staining with phosphotungstic acid ( $\mathrm{pH} 7.2$, adjusted with $\mathrm{NaOH}$ ). Note the granular particles at the bases of the lateral fibrils of the transcriptional unit. (Magn. $\times 51000$.)

FIGURE 7. Negatively stained preparation of nucleolar chromatin from Triturus cristatus oocytes (for details see Franke et al. $1976 b$ ) showing the chromatin axis in the apparent spacer region (denoted by the small arrows) which appears to be 5-8 nm thick under these conditions. (Magn. $\times 130000$.) 


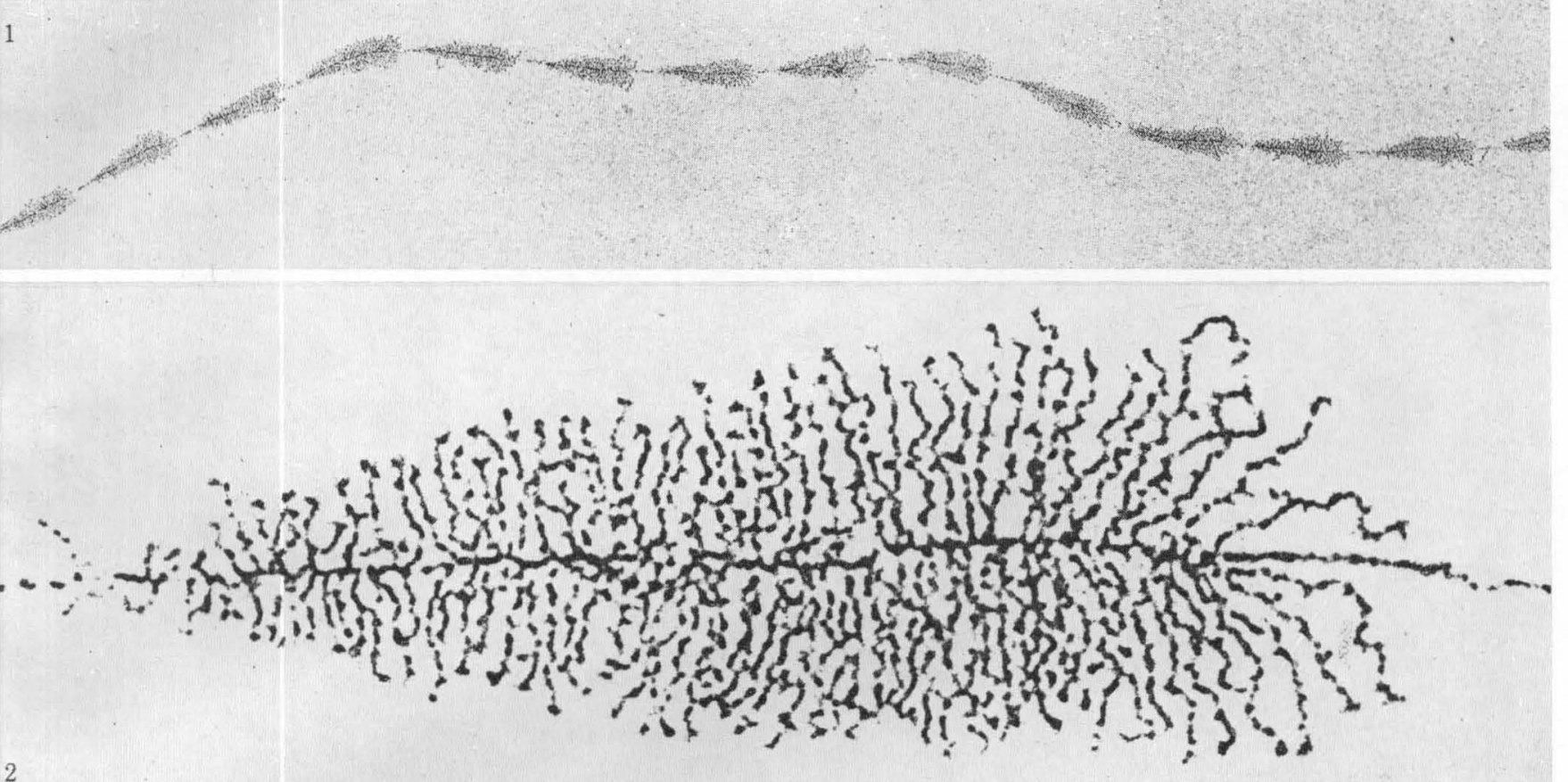

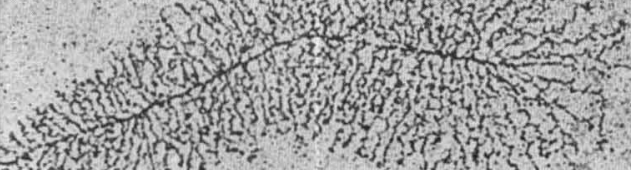

Whathe ras?
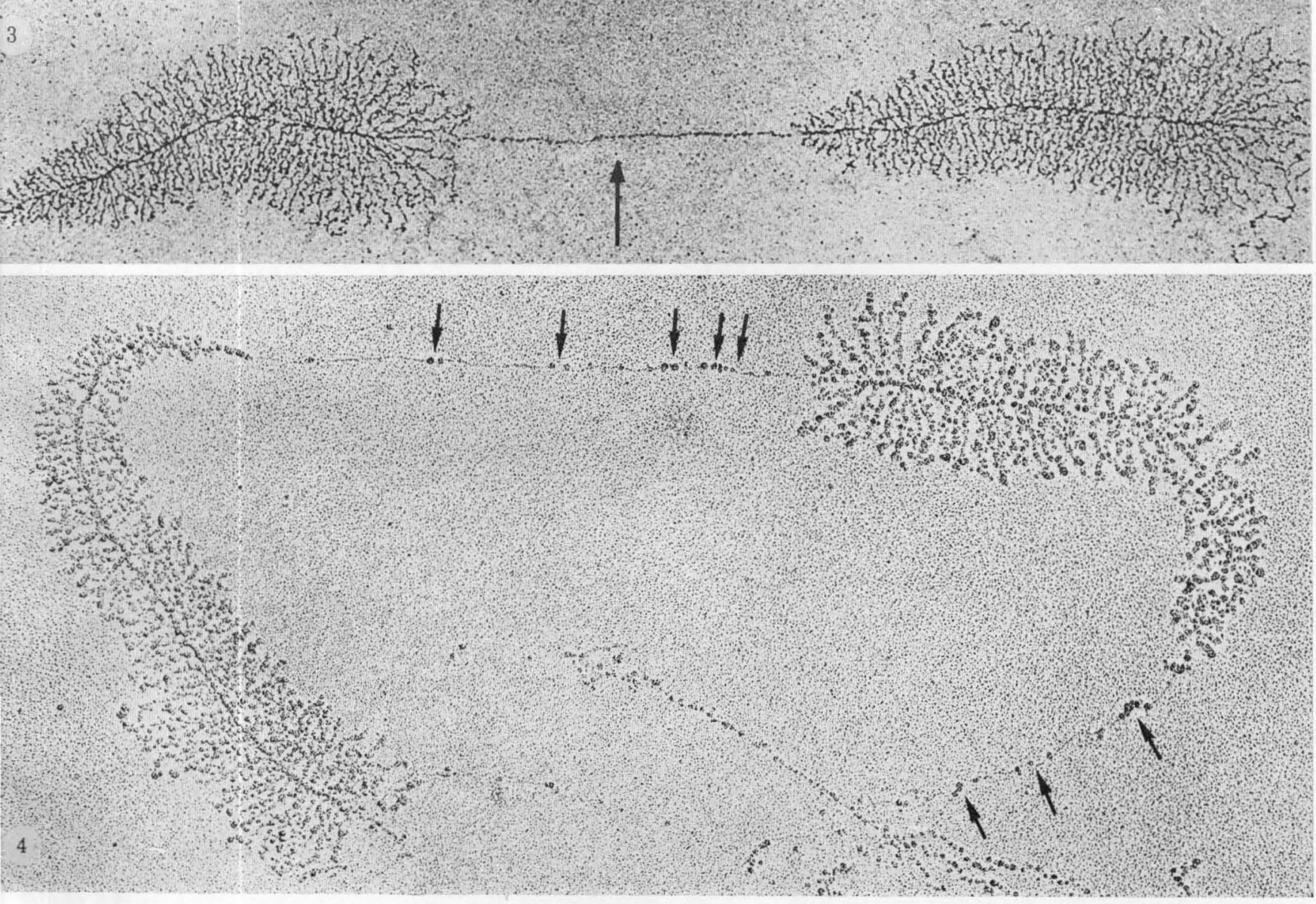

Figures 1-4. For description see opposite.

(Facing p. 336) 


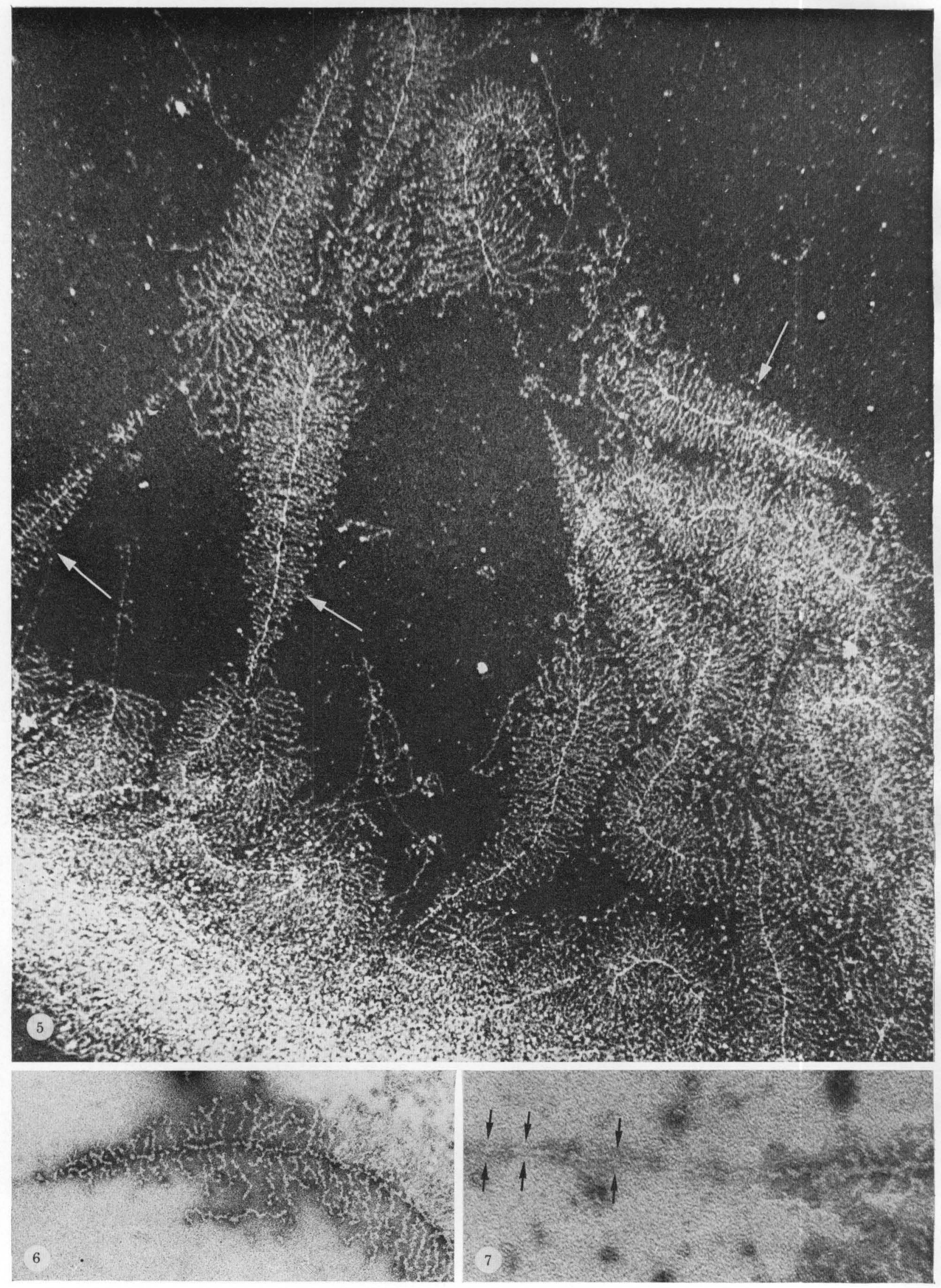

Figures 5-7. For description see page 336. 

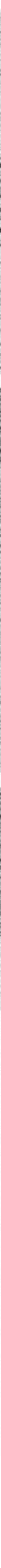

Figures $8,9,11$ And 12. For description see page 337 . 


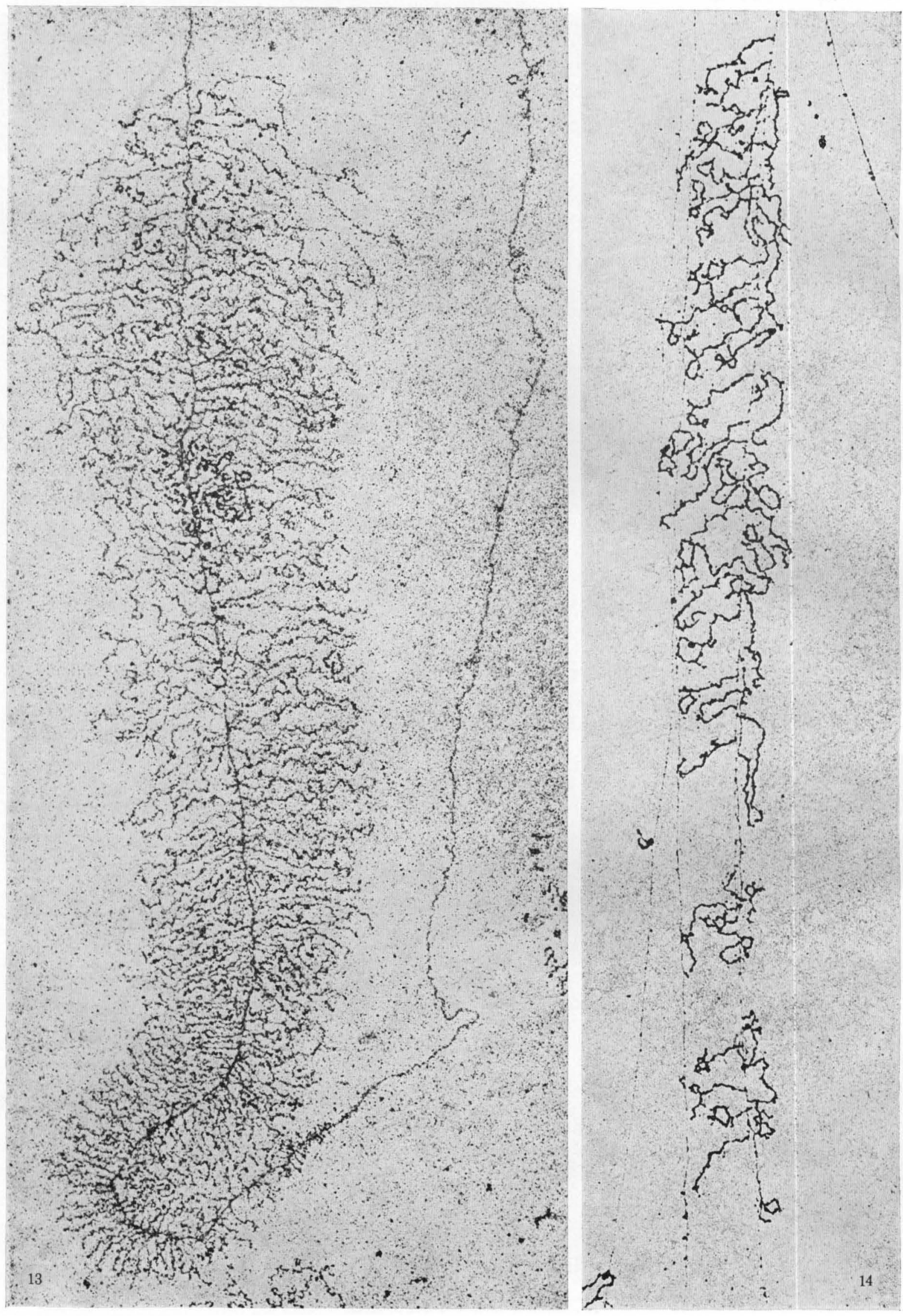

Figures 13 AND 14. For description see opposite. 
The close correspondence of the lengths of repeating units in isolated rDNA and transcriptionally active chromatin also indicates that possible local unwinding of the DNA during transcription (see Bick, Lee \& Thomas 1972) does not result in a considerable overall extension or shortening of the DNA of the pre-rRNA gene region.

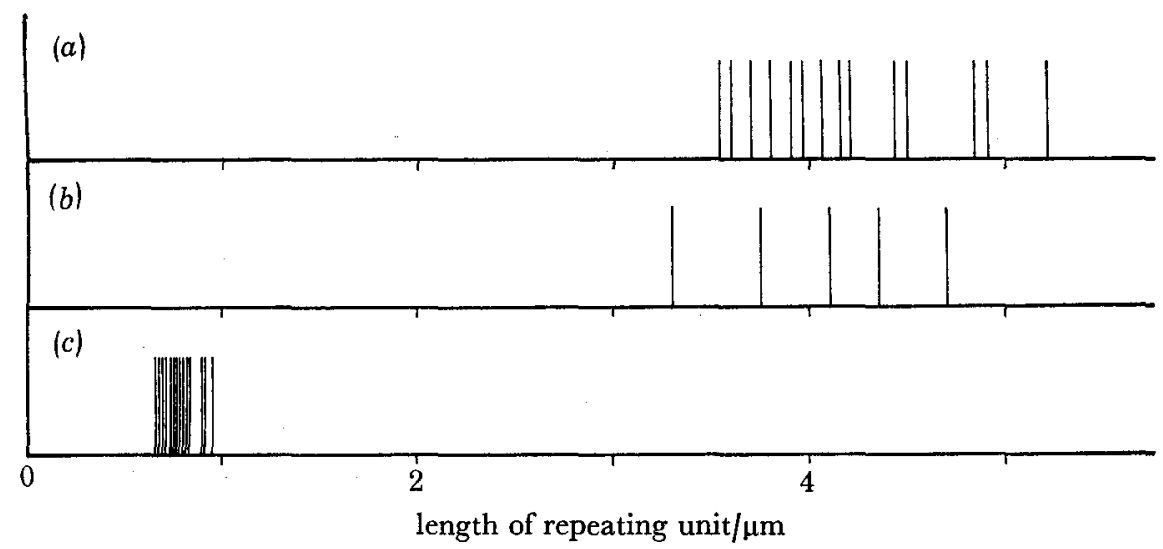

FIGURE 10. Schematic presentation showing a comparison of the distribution of classes of repeat unit lengths in Xenopus laevis rDNA as determined in isolated rDNA $((a)$ values taken from Wellauer et al. $1976 b)$ and in spread preparations of transcribed nucleolar chromatin $(b)$. For comparison, $(c)$ shows the expected distribution of these classes of repeat unit lengths if this DNA were packed into nucleosomes (assuming a packing resulting in a foreshortening of the axis by ca. 5.4; see Oudet et al. 1975).

\section{DESGRIPTION OF PLATE 3}

FIGURE 8. Electron micrograph of a positively stained spread preparation of a ring of nucleolar chromatin isolated from diplotene oocytes of the water beetle, Dytiscus marginalis (for preparative details see Trendelenburg et al. 1976, 1977). This ring contains two transcribed genes coding for precursors to ribosomal RNAs and the interspersed apparent spacer intercepts. (Magn. $\times 30000$.)

FIGURE 9. Sequence of transcriptional units of genes coding for the precursor to ribosomal RNAs in (extrachromosomal) nucleolar material from Xenopus laevis oocytes (for details see Scheer et al. 1977). The measurements of the lengths of the repeating units in such transcriptionally active nucleoli have been compared with the measurements of the lengths of such repeating units in the isolated rDNA (see figure 10). (Magn. $\times 16000$.)

FIGUREs 11 AND 12. Electron micrographs of positively stained spread nucleolar chromatin from oocytes of Triturus cristatus, without (figure 11) and with (figure 12) additional metal shadow cast, treated with $0.3 \%$ Sarkosyl NL-30 for removal of a large proportion of the chromatin-associated proteins. The RNA polymerasecontaining complexes located at the bases of the lateral fibrils are resistant to this pretreatment, which removes most of the histones. Similarly, the granules associated with apparent spacer regions and with other regions free from lateral fibrils are still well identified (some are denoted by arrows in figure 11), indicative of their non-nucleosomal nature. (Magns: figure 11, $\times 65000$; figure 12, $\times 45000$.)

\section{DESGRIPTION OF PLATE 4}

Figure 13. Electron micrograph showing a portion of a positively stained spread lampbrush chromosome loop from an oocyte of Triturus cristatus (for details see Scheer et al. 1976b). One transcriptional (non-nucleolar) unit is recognizable, limited by a preceding and a subsequent fibril-free, i.e. seemingly non-transcribed, region of the loop chromatin axis. (Magn. $\times 21000$.)

FIGURE 14. Similar preparation of non-nucleolar chromatin from oocytes of Triturus cristatus showing loop axes with a markedly reduced density of lateral fibrils which contain the nascent non-pre-rRNA transcripts. Note the absence of granular particles of nucleosomal size in most parts of the fibril-free portions of the axes. (Magn. $\times 28000$.) 
TRANSCRIPTIONAL UNITS OF GENES CODING FOR PREGURSORS TO RIBOSOMAL RNAS AT REDUGED DENSITIES OF TRANSGRIPTIONAL GOMPLEXES

Considerable reduction of transcription is frequently recognized by a lowered number of lateral fibrils per transcriptional unit or by the complete absence of lateral fibrils in some of the genes of a pre-rRNA gene cluster (Scheer et al. $1976 a$ ). Similarly, the inhibition of RNA synthesis by certain drugs results in the release of lateral fibrils containing immature pre-rRNA molecules from the nucleolar chromatin strands (Scheer, Trendelenburg \& Franke 1975). Intercepts of nucleolar chromatin strands within a pre-rRNA gene region which are not associated with lateral fibrils usually do not show particles of nucleosomal size (see, for example, figure 12; Franke et al. $1976 b$ ). The length distribution of repeating units, however, is not significantly altered in such states of reduced or, for short periods of time, inhibited transcription (see Franke et al. 1976 b). This indicates that chromatin regions devoid of transcriptional complexes that are located on strands which contain some lateral fibrils in other regions are also not packed and condensed into nucleosomes.

\section{APPARENT SPAGER UNITS BETWEEN THE GENES GODING FOR RIBOSOMAL RNAS}

Spacer regions interspersed between the pre-rRNA genes are either associated with specific groups of lateral fibrils indicative of the transcription of some spacer DNA simultaneously with the synthesis of the pre-rRNA (as to the special problems of the interpretation of transcriptional phenomena in rDNAspacer regions see Franke et al. (1976a) and Scheer et al. (1977)), or are free of lateral fibrils. The latter is the most commonly found situation (figures 1-4, 7-9). Whereas such spacer regions often show a chromatin axis of rather uniform width of $5-8 \mathrm{~nm}$ diameter (figures $2,3,7$ ) attached $12-18 \mathrm{~nm}$ granular particles are observed in some spacer intercepts, usually in variable numbers and patterns of arrangement (figure 4; cf. Scheer et al. 1976; Franke et al. 1976b). Such granular particles have been interpreted by some authors as RNA polymerase complexes without visible associated RNP fibrils, be this an in vivo situation or be it artificially induced (for references see Miller \& Beatty (r969) and Franke et al. (1976b)). Other authors, however, have hypothesized that they might represent nucleosomes (see, for example, Laird et al. 1976; Woodcock et al. 1976a). However, quantitative evaluations of spread preparations of nucleolar chromatin from newt oocytes (Franke et al. 1976b) have shown that the number of such granules per apparent spacer unit is not inversely proportional to the length of the specific spacer unit, as one would expect if these particles were nucleosomes in which DNA fibres are significantly foreshortened (for reported figures of packing ratios and fibre contour foreshortening see, for example, Germond et al. 1975; Griffith 1975; Oudet, Gross-Bellard \& Chambon 1975; Carlson \& Olins 1976; Cremisi, Pignatti, Croissant \& Yaniv 1976; Sperling \& Tardieu 1976; Woodcock, Sweetman \& Frado 1976c; Varshavsky, Bakayev, Chumackov \& Georgiev 1976). That the DNA contained in the spacer regions of transcribed nucleolar chromatin is not considerably condensed into nucleosomal structures is also again apparent from the comparison of the total repeating unit lengths of rDNA isolated from Xenopus laevis with the repeating units recognized in spread nucleoli from the oocytes of this organism (Scheer et al. 1977; for references see also above). This holds in particular for the comparison of the shortest repeat unit classes. In this connection it is also interesting to 
recall to mind the correspondence of contour lengths of circles of rDNA and circles of transcribed nuceolar chromatin in the oocytes of the water beetle, Dytiscus marginalis, and the house cricket, Acheta domesticus, which has already been mentioned.

\section{NON-NUGLEOLAR TRANSGRIPTIONAL UNITS AND ADJACENT APPARENT SPAGER REGIONS}

Transcriptional units of high or reduced density of lateral fibrils which are different from genes coding for pre-rRNA in matrix unit length and in lateral fibril length and morphology are not clustered, and are characterized by a marked length heterogeneity, have been described in chromatin from various cell types and, in particular detail, in the loops of lampbrush chromosomes of amphibian oocytes and the green alga Acetabularia (Miller \& Bakken 1972; Spring et al. 1974; Foe et al. 1976; Laird et al. 1976; McKnight et al. 1976; Scheer et al. 1976 b (see there for further references); Puvion-Dutilleul et al. 1977). Occasionally, however, individual, relatively large matrix units have also been noted in nucleolar chromatin (Spring et al. 1974; Spring et al. 1976). Such matrix units are usually interpreted as transcriptional units of genes coding for non-pre-rRNA molecules, most probably Hn-RNAs (pre-mRNAs; for discussion see references mentioned above). Figures 13 and 14, plate 4, illustrate the appearance of such matrix units with dense (figure 13) and reduced (figure 14) fibril coverage. Again, particles of nucleosomal size that are not connected with a lateral fibril seem to be absent in matrix units characterized by a high packing density of lateral fibrils, and it seems unlikely that there would be space for such particles in arrays of almost maximal packing of RNA polymerase B-type molecules (for detailed discussion see Franke et al. (1976b); see also, for example, Miller \& Bakken (1972) and McKnight \& Miller (1976)). Non-nucleolar matrix units of reduced fibril densities often reveal intercepts of 'clear' chromatin axis not associated with nucleosome-like particles (figure 14; cf. Franke et al. 1976b; Scheer et al. 1976b). In some chromatin preparations and in some loop axes, however, particles of nucleosomal size not associated with lateral fibrils are observed which we tentatively interpret as nucleosomal, a view which seems to be supported by the removal of some at least of these particles by the detergent treatment mentioned in the previous paragraphs (cf. Scheer et al. 1977). Other authors have also interpreted such granules as nucleosomes that result in the local packing of regions of DNA within a transcriptional unit (see, for example, Kierszenbaum \& Tres 1975; Foe et al. 1976; Laird et al. 1976). Apparent spacer regions in between such non-pre-rRNA, non-nucleolar transcriptional units are also frequently found devoid of attached granules. Whether or not the granules observed in some preparations in such fibril-free regions are of nucleosomal or non-nucleosomal nature cannot be said at the moment.

\section{Discussion}

Our observations indicate that in transcriptionally active chromatin DNA is not packed into 10-12 nm nucleosomes but is present in an extended form in a different deoxyribonucleoprotein organization. This appears to be especially evident for the genes coding for the precursors to the $28 S$ and $18 S$ ribosomal RNAs. The recent report by Higashinakagawa, Wahn \& Reeder (1977) who found polypeptides co-migrating in SDS-polyacrylamide gel electrophoretic systems with histones in nucleoli-enriched fractions from Xenopus laevis stage II and III oocytes 
suggests that histones are present in such transcriptionally active nucleolar chromatin (although the degree of transcriptional activity at these stages has not yet been determined). The concept of an absence of nucleosomal globules in transcribed genes of ribosomal RNAs seems to be in conflict with reports of the protection of $c a .200$ base pair units of rDNA to digestion with endonuclease in macronuclei of the ciliate, Tetrahymena pyriformis (Leer, Nielsen, Piper \& Westergaard 1976; Mathis \& Gorovsky 1976; Piper et al. 1976), and in somatic cells of Xenopus laevis (Reeves 1976; Reeies \& Jones 1976). In both systems, however, the number of transcribed genes has to be regarded as unknown. Interestingly, the data presented by Reeves (1976) and

(a)

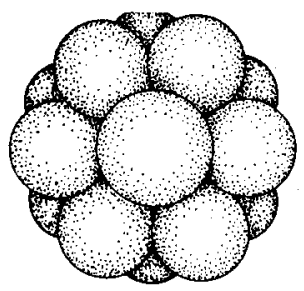

(b)

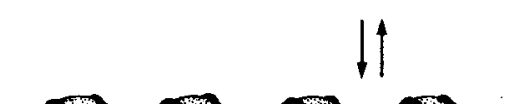

b)

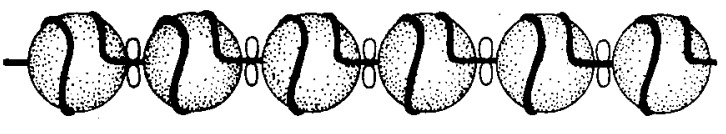

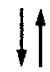

(c)
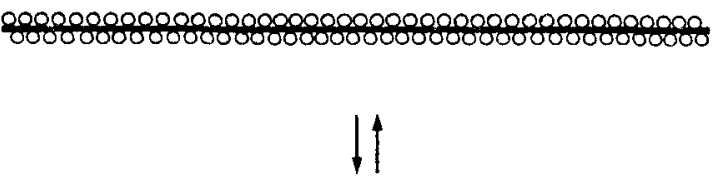

(d)

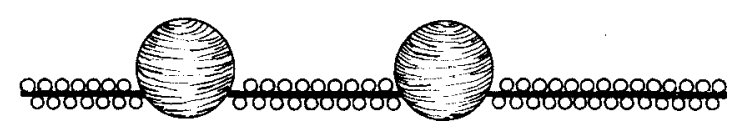

(e)

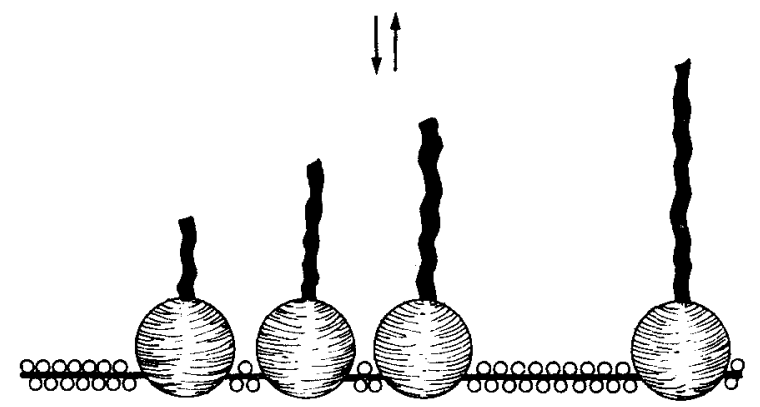

FIGURE 15. Schematic drawing which illustrates different forms of chromatin organization such as the nucleosomal strand $(b)$, the higher order of packing of the $12 \mathrm{~nm}$ nucleosomes into larger globules of 20-30 nm diameter $(a)$, an extended deoxyribonucleoprotein strand $(c)$, an extended chromatin strand with attached RNA polymerase complexes $(d)$, and transcriptionally active chromatin (e) with lateral ribonucleoprotein fibrils that contain the nascent RNA associated with the RNA polymerase and the template-containing strand. The arrows denote possible structural transitions. The hypothetical sequence from $a$ to $e$ would represent a crude scheme of possible structural changes that might be involved in the transcriptional activation of chromatin. 
Reeves \& Jones (1976) rather tend to indicate that the higher the rate of production of $28 \mathrm{~S}$ and $18 S \mathrm{rRNAs}$ the lower is the amount of $\mathrm{rDNA}$ recovered in nucleosomes protected against digestion with micrococcal nuclease.

The extension of this concept of a reduction and disappearance of 10-12 nm nucleosomes in transcriptionally active chromatin to non-nucleolar genes, in particular to those coding for mRNAs, is not contradicted by present morphological data but here this view is still insufficiently substantiated. As already mentioned several other authors have interpreted dense granules located on chromatin strands but not associated with lateral fibrils as nucleosomes, and Laird et al. (1976), for example, have calculated DNA packing ratios ( $\mu \mathrm{m} \mathrm{DNA} / \mu \mathrm{m}$ chromatin) ranging from 1.6 to 2.3 for various types of chromatin from Oncopeltus and Drosophila. In addition, our concept seems to be in conflict with recent reports of the inclusion of sequences of transcribed genes coding for mRNAs in nucleosomes obtained by digestion of chromatin with endonuclease treatment (see, for example, Brown, Heikkila \& Straus 1976; Garel \& Axel 1976; Kuo, Sahasrabuddhe \& Saunders 1976; Tata \& Baker 1976) and in particles prepared from transcriptionally active chromatin subfractions (see Gottesfeld 1978 , this symposium). Again, however, in discussing some of these experiments it has to be kept in mind that the number of actually transcribed genes per nucleus and/or the degree of homogeneity of the nuclear populations used has not been clarified.

In view of the observation that nuclear DNA can be found in various forms of chromatin organization it seems to be an excusable speculation to propose that at least some of these forms might be related to, or might reflect, different states of transcriptional activity and activation. The arrangement of DNA in nucleosomes and in solenoidal (Finch \& Klug 1976; see also Davies \& Haynes 1976) or granular (Zentgraf, Falk \& Franke 1975; Franke et al. $1976 b$; Kiryanov et al. 1976; Renz, Nehls \& Hosier 1977) structures of higher order of nucleosomal packing is certainly present in transcriptionally inactive chromatin, a good portion of which appears to be contained in typical 'condensed' chromatin. Thus, the dispersion of a certain region of DNA or chromatin and/or its transition into a transcriptionally active state might involve a general change in the chromatin architecture (shown schematically in figure 15). Such a structural transition might occur in one step or in a series of steps via discrete intermediate forms.

We thank our colleagues Dr H. Zentgraf and Dr H. Zerban as well as Dipl. Biol. H. Spring and M. F. Trendelenburg for valuable discussions and contributions and for help in the preparation of the manuscript.

\section{REFERENGES (Franke \& Scheer)}

Berkowitz, E. M. \& Doty, P. 1975 Proc. natn. Acad. Sci. U.S.A. 72, 3328-3332.

Bick, M. D., Lee, C. S. \& Thomas, C. A. Jr 1972 J. molec. Biol. 71, 1-9.

Brown, I. R., Heikkila, J. J. \& Straus, N. A. 1976 J. Cell Biol. 70, 121a.

Buongiorno-Nardelli, M., Amaldi, F., Beccari, E. \& Junakovic, N. 1977 J. molec. Biol. 110, $105-117$.

Carlson, R. D. \& Olins, D. E. 1976 Nucl. Acids Res. 3, 89-100.

Cremisi, C., Pignatti, P. F., Croissant, O. \& Yaniv, M. r976 J. Virol. 17, 204-211.

Daneholt, B., Case, S. T., Lamb, M. M., Nelson, L. \& Wieslander, L. 1978 Phil. Trans. R. Soc. Lond. B 283, 383-389 (this volume).

Davies, H. G. \& Haynes, M. E. 1976 J. Cell Sci. 21, 315-327.

Finch, J. T. \& Klug, A. 1976 Proc. natn. Acad. Sci. U.S.A. 73, 1897-1901. 
Foe, V. E., Wilkinson, L. E. \& Laird, G. D. 1976 Cell 9, 131-146.

Franke, W. W., Scheer, U., Spring, H., Trendelenburg, M. F. \& Krohne, G. I976 a Expl Cell Res. 100, $233-244$. Franke, W. W., Scheer, U., Trendelenburg, M. F., Spring, H. \& Zentgraf, H. $1976 b$ Cytobiologie 13, 401-434. Garel, A. \& Axel, R. 1976 Proc. natn. Acad. Sci. U.S.A. 73, 3966-3970.

Gariglio, P. 1976 Differentiation 5, 179-183.

Germond, J. E., Hirt, B., Oudet, P., Gross-Bellard, M. \& Chambon, P. 1975 Proc. natn. Acad. Sci. U.S.A. 72, 1843-1847.

Gottesfeld, J. M. 1978 Phil. Trans. R. Soc. Lond. B 283, 343-357 (this volume).

Griffith, J. D. I975 Science, N.Y. 187, 1202-1203.

Heitz, E. I932 Planta 18, 571-637.

Higashinakagawa, T., Wahn, H. \& Reeder, R. H. 1977 Devl. Biol. 55, 375-386.

Kierszenbaum, A. L. \& Tres, L. L. 1975 J. Cell Biol. 65, 258-270.

Kiryanov, G. I., Manamshjan, T. A., Polyakov, V. Y., Fais, D. \& Chentsov, J. S. 1976 FEBS Lett. 67, 323-327.

Krieg, P. \& Wells, J. R. E. 1976 Biochemistry, N.Y. 15, 4549-4558.

Kuo, M. T., Sahasrabuddhe, G. G. \& Saunders, G. F. 1976 Proc. natn. Acad. Sci. U.S.A. 73, 1572-1575.

Laird, C. D., Wilkinson, L. E., Foe, V. E. \& Chooi, W. Y. I976 Chromosoma 58, 169-192.

Leer, J. G., Nielsen, O. F., Piper, P. W. \& Westergaard, O. I976 Biochem. biophys. Res. Comm. 72, 720-731.

Mathis, D. J. \& Gorovsky, M. A. 1976 Biochemistry, N.Y. 15, 750-755.

McKnight, S. L. \& Miller, O. L. Jr 1976 Cell 8, 305-319.

McKnight, S. L., Sullivan, N. L. \& Miller, O. L. Jr 1976 In Progress in nucleic acid research and molecular biology (eds W. E. Cohn \& E. Volkin), vol. 19, pp. 313-318.

Miller, O. L. Jr \& Bakken, A. H. I972 Acta endocr., Copenh., suppl. 168, 155-177.

Miller, O. L. Jr \& Beatty, B. R. 1972 Genetics, suppl. 61, 134-143.

Olins, A. L. \& Olins, D. E. I974 Science, N.Y. 183, 330-332.

Oudet, P., Gross-Bellard, M. \& Chambon, P. 1975 Cell 4, 281-300.

Piper, P. W., Celis, J., Kaltoft, K., Leer, J. G., Nielsen, O. F. \& Westergaard, O. 1976 Nucl. Acids Res. 3, 493-505.

Puvion-Dutilleul, F., Bernadac, A., Puvion, E. \& Bernhard, W. 1977 J. ultrastruct. Res. 58, 108-117.

Reeves, R. I976 Science, N.Y. 194, 529-532.

Reeves, R. \& Jones, A. 1976 Nature, Lond. 260, 495-500.

Renz, M., Nehls, P. \& Hozier, J. I977 Proc. natn. Acad. Sci. U.S.A. 74, 1879-1884.

Rickwood, D. \& Birnie, G. D. 1976 In Subnuclear components (ed. G. D. Birnie), pp. 129-186. London and Boston: Butterworths.

Scheer, U., Franke, W. W., Trendelenburg, M. F. \& Spring, H. 1976b J. Cell Sci. 22, 503-519.

Scheer, U., Trendelenburg, M. F. \& Franke, W. W. I975 J. Cell Biol. 65, 163-179.

Scheer, U., Trendelenburg, M. F. \& Franke, W. W. I976 a J. Cell Biol. 69, 465-489.

Scheer, U., Trendelenburg, M. F., Krohne, G. \& Franke, W. W. I977 Chromosoma 60, 147-167.

Sommerville, J., Malcolm, D. B. \& Callan, H. G. I978 Phil. Trans. R. Soc. Lond. B 283, 359-366 (this volume). Sperling, L. \& Tardieu, A. 1976 FEBS Lett. 64, 89-91.

Spring, H., Krohne, G., Franke, W. W., Scheer, U. \& Trendelenburg, M. F. 1976 J. Microsc. Biol. cell. 25, 107-116.

Spring, H., Trendelenburg, M. F., Scheer, U., Franke, W. W. \& Herth, W. x974 Cytobiologie 10, 1-65.

Tata, J. R. \& Baker, B. I 976 J. Cell Biol. 70, 219 a.

Trendelenburg, M. F., Franke, W. W. \& Scheer, U. 1977 Differentiation 7, 133-158.

Trendelenburg, M. F., Scheer, U., Zentgraf, H. \& Franke, W. W. 1976 J. molec. Biol. 108, 453-470.

Trendelenburg, M. F., Spring, H., Scheer, U. \& Franke, W. W. 1974 Proc. natn. Acad. Sci. U.S.A. 71, 3626-3630.

Varshavsky, A. J., Bakayev, V. V., Chumackov, P. M. \& Georgiev, G. P. 1976 Nucl. Acids Res. 3, 2101-2113.

Wellauer, P. K. \& Reeder, R. H. 1975 J. molec. Biol. 94, 151-161.

Wellauer, P. K., Dawid, I. B., Brown, D. D. \& Reeder, R. H. I976a J. molec. Biol. 105, 461-486.

Wellauer, P. K., Reeder, R. H., Carroll, D., Brown, D. D., Deutch, A., Higashinakagawa, T. \& Dawid, I. B. 1974 Proc. natn. Acad. Sci. U.S.A. 71, 2823-2827.

Wellauer, P. K., Reeder, R. H., Dawid, I. B. \& Brown, D. D. I976b J. molec. Biol. 105, 487-505.

Woodcock, G. L. F., Frado, L.-L. Y., Hatch, C. L. \& Ricciardiello, L. I976a Chromosoma 58, 33-39.

Woodcock, C. L. F., Safer, J. P. \& Stanchfield, J. E. I976b Expl Cell Res. 97, 101-110.

Woodcock, C. L. F., Sweetman, H. E. \& Frado, L.-L. 1976c Expl Cell Res. 97, 111-119.

Zentgraf, H., Falk, H. \& Franke, W. W. I975 Cytobologie 11, 10-29. 